TITLE:

\title{
Optimization of biodiesel production by supercritical methyl acetate.
}

\author{
$\operatorname{AUTHOR}(\mathrm{S})$ :
}

Goembira, Fadjar; Saka, Shiro

CITATION:

Goembira, Fadjar ...[et al]. Optimization of biodiesel production by supercritical methyl acetate.. Bioresource technology 2012, 131: 47-52

ISSUE DATE:

2012-12

URL:

http://hdl.handle.net/2433/169706

\section{RIGHT:}

C 2012 Elsevier Ltd.; この論文は出版社版でありません。引用の際には 出版社版をご確認ご利用ください。; This is not the published version. Please cite only the published version. 


\section{Optimization of Biodiesel Production by Superc nitical Methyl Acetate*}

Fadjar Goembira and Shiro Saka**

Department of Socio-Environmental Energy Science

Graduate School of Energy Science

Kyoto University

Yoshida-honmachi, Sakyo-ku, Kyoto 606-8501, Japan

**Corresponding author

E-mail a ddress: saka @energy.kyoto-u.ac.jp

*This work is an excerpt of PhD dissertation by F. Goembira in Kyoto University who is presently in Department of Environmental Engineering, Fac ulty of Engineering, Anda la s University, Indonesia 


\begin{abstract}
This work has been done to find out the optimum condition of supercritical methyl acetate method in biodiesel production. The reaction temperature, pressure, time and molar ratio in methyl acetate to oil were the key parameters that must all be considered to produce an optimum condition. Evaluation of thermal decomposition on products, cis-trans isomerization and tocopherol content were required to further optimize the reaction condition. It was, therefore, concluded that for the supercritical methyl acetate method, reaction condition of $350^{\circ} \mathrm{C} / 20 \mathrm{MPa} / 45 \mathrm{~min} / 42$ molar ratio gave the highest yields of FAME (96.7wt\%) and triacetin (8.8wt\%). Yet, at such a reaction condition, the optimum reaction condition was compromised due particularly to the unavoidable thermal decomposition of products, and tocopherols as natural anti-oxidants.
\end{abstract}

Keywords: biodiesel, optimization, supercritical methyl acetate, triacetin 


\section{Introduction}

Due to the increasing worldwide concerns of excess glycerol production on the marketplace from biodiesel (Bonet et al., 2009), a new method in biodiesel production that prevents glycerol production must be developed. A non-catalytic supercritical methyl acetate reaction can be utilized to avoid the production of glycerol during biodiesel production (Saka, 2005). Instead of forming glycerol, the supercritical method produces triacetin as its by-product. Stoichiometrically, 3 moles of fatty acid methyl esters (FAME) and 1 mole of triacetin are produced from every 1 mole of triglycerides.

Furthermore, Saka and Isayama (2009) have reported that triacetin, a by-product from interesterification of triglycerides, is miscible with FAME even at room temperature and atmospheric pressure. This mixture hardly has any negative effect on the resultant biodiesel, in fact, it improves some of biodiesel properties, such as viscosity, oxidation stability and cold-flow properties. Therefore, the mixture of FAME and triacetin can be considered as biodiesel resulting in a maximum theoretical yield of $125 \mathrm{wt} \%$ from the interesterification reaction of triglycerides (Saka and Isayama, 2009). In addition, Goembira et al. (2012) further reported that supercritical methyl acetate acquires the highest yield among various supercritical carboxylate esters in biodiesel production. 
Due to the potential of the supercritical method, it has been studied by other research groups (Campanelli et al., 2010; Niza et al., 2011 ; Tan et al., 2010, 2011). Some of them (Tan et al., 2010, 2011; Niza et al., 2011 ) claimed that the reaction conditions used in their studies were optimized. However, the obtainable yields were far below the maximum theoretical yield of $125 \mathrm{wt} \%$.

This study has been undertaken to show key parameters that must be considered before attaining optimum reaction conditions. Additionally, this work was done along the line of our previous Letter to the Editor (Saka et al., 2011).

\section{Experimental}

\subsection{Matenials}

Rapeseed oil was used in this experiment as the source of triglycerides, consisting of $99.8 w+\%$ triglyceride content. High purity chemicals such as methyl acetate, various FAME and triacetin were utilized, whereas for standard compounds, analytical grade of individual FAME, triacetin and tocopherols were used. All chemicals were purchased from Nacalai Tesque Inc., Kyoto, Japan.

\subsection{Methods}

Supercritical methyl acetate treatment was carried out by using a flow-type reaction system to study the effect of molar ratio in methyl acetate to oil, reaction pressure, reaction temperature and reaction 
time on product yields. The flow-type reaction system was the same as the one reported previously (Saka and Isayama, 2009). On the other hand, a batch-type reaction system was utilized for experiments on thermal decomposition of products, c is-trans isomerization of FAME and tocopherol degradation. The batch-type reaction vessel was equipped with an additional gas charging inlet for purging the vessel with nitrogen. Furthermore, additional initial pressure can be added by charging nitrogen, thereby a designated reaction pressure being obtainable.

Quantifications of FAME, triacetin and tocopherols were carried out by using high performance liquid chromatography (HPLC), with methanol as the mobile phase. Refractive index detector (RID) was used for FAME and triacetin, while fluorescent detector was applied for tocopherols. The HPLC setting for the RID was the same as the one used by Goembira et al.(2012), whereas for the fluorescent detector was similar to the work by Xin et al. (2008). Moreover, evaluation of cis-trans isomerization of FAME was made by using fourier transform infra red (FTIR). All sets of experiments were done in triplicate with less than $1 \%$ variation in the results, indicating that they can be replicated in a high precision state.

\section{Results and disc ussion}

\subsection{Effect of molar ratio of methyl acetate to oil on product yield}

As explained earlier, 3 moles of methyl acetate is stoichiometrically needed to convert 1 mole of triglycerides into 3 moles 
of FAME and 1 mole of triacetin. Nevertheless, in order to proceed the reaction towards the product side, an excessive amount of methyl acetate must be applied.

Fig. 1 shows the effect of molar ratio in methyl acetate to rapeseed oil on the yields of FAME and triacetin. It can be seen from Fig. 1 that the higher molar ratio resulted in the higher FAME and triacetin yields. This is due to the availability of excess reactants for reactions to proceed and the prevention of backward reaction. The formation of FAME could firstly be observed when the molar ratio was set at 6:1, nonetheless, molar ratio of $42: 1$ was required in order to obtain FAME yield higher than $96.5 \mathrm{wt} \%$, as the minimum ester content in European biodiesel standard (EN-14214). On the other hand, triacetin was formed at molar ratio of $21: 1$, which was higher than molar ratio for the initial formation of FAME.

A molar ratio increase from 42:1 to 54:1, however, did not significantly increase the yield. FAME yield was only increased from 96.7 to $97.2 w+\%$, while for triacetin, it increased from 8.8 to $9.0 w+\%$. Insignificant yield increase at the higher molar ratio than 42:1 was presumably due to an additional role of the solvent to minimize the occurrence of thermal decomposition. The excessive amount of solvent inhibits thermal decomposition of product by a cage-effect mechanism (Ehara et al., 2002). Similar result was reported by Campanelli et al. 
(2010), although different biodiesel feedstock was used in their experiment.

Conversely, different trend line was reported by Tan et al. (2011), where the higher molar ratio than 30:1 resulted in the lower yield. They explain the phenomenon was due to difficulties in separating the products from the unreacted methyl acetate, which is unacceptable because there should be no problem in removing methyl acetate from the mixture of FAME and triacetin since their boiling points (at latm) are so much different, i.e. 57,374 and $260^{\circ} \mathrm{C}$, respectively.

\subsection{Effect of reaction pressure on product yield}

Fig. 2 shows the effect of reaction pressure on biodiesel yield in supercritical methyl acetate treatment. Reaction pressure higher than critical pressure of methyl acetate ( $\mathrm{PC}=4.69 \mathrm{MPa})$ was required to ascertain that the supercritical state has been attained.

However, Fig. 2 shows that at reaction pressure of 5MPa, no FAME and triacetin formations were observed. Gil et al. (2008) stated that there is a possibility of changes in the critical pressure of a binary mixture. It is presumed that the critical pressure of the binary mixture of oil and solvent was higher than $5 \mathrm{MPa}$. The use of $5 \mathrm{MPa}$ in reaction pressure, therefore, resulted in the absence of FAME and triacetin due presumably to the unreached supercritical state of the binary mixture.

It is obvious from Fig. 2 that the higher reaction pressure resulted in the higher yields of FAME and triacetin, possibly due to the higher 
density of the reactant mixture that increased the occurrence of collisions among reactant molecules noted by Turro (2005). However, no increase in the yield of triacetin up to reaction pressure of $15 \mathrm{MPa}$. This phenomenon could be due to the fact that the formation of triacetin must be initiated by inducing complete acyl replacement in the glycerol backbone with $\mathrm{CH}_{3} \mathrm{COO}^{-}$from methyl acetate. At reaction pressures of 20 and $30 \mathrm{MPa}$, complete acyl replacement occurred.

Nevertheless, insignificant increases in yields of FAME from 96.7 to $98.1 \mathrm{w}+\%$ and triacetin from 8.8 to $8.9 \mathrm{w}+\%$ were noted when the reaction pressure was increased from 20 to $30 \mathrm{MPa}$. This slight yield increase could be due to the role of the higher reaction pressure in minimizing thermal decomposition of products as well as the higher interesterification.

\subsection{Effect of reaction temperature on product yield}

In general, the higher reaction temperatures would result in the higher reaction rates, which eventually correspond to the higher biodiesel yields. This can evidently be seen in Fig. 3, where the higher reaction temperature under the same pressure of $20 \mathrm{MPa}$ contributed to the higher biodiesel yield.

However, Fig. 3 also shows that at $300^{\circ} \mathrm{C}$ there was no observable product formation. Meanwhile, starting from $320^{\circ} \mathrm{C}$, biodiesel will be formed, although the yield was still below 50wt\%. These lines of evidence show that in the non-catalytic reaction, reactivity of triglycerides 
towards supercritical methyl acetate was relatively low, particularly at reaction temperatures below $320^{\circ} \mathrm{C}$.

The highest total yield of $105.5 w+\% \quad$ (96.7wt\% FAME; 8.8wt\% triacetin) was acquired at reaction condition of $350^{\circ} \mathrm{C} / 20 \mathrm{MPa} / 45 \mathrm{~min}$. The yield of this study was relatively higher compared to the other research groups. Campanelli et al. (2010) obtained 104.0 wt\% under the same reaction temperature used in this study. However, Niza et al. (2011) and Tan et al. (2011) could only obtain 71.9 for J atropha oil and 99wt\% for palm oil, correspondingly, at a much severe reaction condition of $400^{\circ} \mathrm{C}$, although palm oil can be expected to be higher yield due to the less amount of poly-unsaturated fatty acids.

\subsection{Effect of reaction time on product yield}

The effect of reaction time on FAME and triacetin yields can be evaluated from Figs. 1 through 3. As we can see from the figures, in most cases, the longer reaction time resulted in the higher FAME yields. This situation was due to the fact that the longer reaction time has increased the contact time of the solvent with triglycerides and the intermediate compounds.

In Fig. 3, we can also see that in some cases, particularly at the higher reaction temperatures that the biodiesel yield was increased to a certain extent, but it was decreased over a prolonged reaction time. The reaction time of only $15 \mathrm{~min}$ was required to obtain total yield of 90.8wt\% (76.4wt\% FAME; 14.4 wt\% triacetin) when reaction condition of 
$380^{\circ} \mathrm{C} / 20 \mathrm{MPa}$ was used, while under $350^{\circ} \mathrm{C} / 20 \mathrm{MPa}$, a comparable total yield of $91.94 \mathrm{wt} \%$ (84.5wt\% FAME; $7.5 \mathrm{w}+\%$ triacetin) will only be achieved in 30min reaction time. Nevertheless, in the former case, longer reaction time up to $45 \mathrm{~min}$ could only slightly increase the total yield up to 97.7wt\% (86.7wt\% FAME; 10.9wt\% triacetin), whereas for the latter case, the total yield of $105.5 \mathrm{wt \%} \quad$ (96.7wt\% FAME; $8.8 \mathrm{wt \%}$ triacetin) was obtainable under the same reaction time.

The similarity of the two reaction conditions was the yield decrease at reaction time longer than $45 \mathrm{~min}$. At $60 \mathrm{~min}$ reaction time, total yields were 80.6 (75.3wt\% FAME; 5.3wt\% triacetin) and $98.1 \mathrm{w}+\%$ (90.7wt\% FAME; $7.4 \mathrm{wt} \%$ triacetin) under 380 and $350^{\circ} \mathrm{C}$ reaction temperatures, respectively. Although applying different feedstocks and reaction conditions in supercritical methyl acetate treatments, however, the yield reduction under the higher reaction temperatures was also observed by the other research groups (Campanelli et al., 2010; Niza et al., 2011 ; Tan et al., 2011 ). It is most likely that this situation was due to the occurrence of thermal decomposition.

\subsection{Themal decomposition of individual fatty acid methyl esters (FAME) and triacetin}

Fig. 4 shows the recovery of individual FAME and triacetin after exposure to various reaction temperatures under the same reaction pressure of 20MPa. We can clearly observe the occurrence of severe thermal decomposition in all products at $380^{\circ} \mathrm{C}$, particularly when longer 
reaction time was applied. On the other hand, at reaction condition of $350^{\circ} \mathrm{C}$, only methyl linolenate exhibited significant thermal decomposition. Furthermore, a reaction temperature of $300^{\circ} \mathrm{C}$ gave the least thermal decomposition, in good agreement with the results presented by Imahara et al. (2008) for conversion by supercritical methanol.

Oils from rapeseed (Brassica napus) and oil palm (Elaeis guineensis) were also utilized to compare the effect of thermal decompositions on biodiesel feedstocks that have different degrees of unsaturation. As can be seen from Table 1, rapeseed oil represented biodiesel feedstocks with a high degree of unsaturation, while on the other hand, palm oil was corresponding to feedstocks with a lower degree of unsaturation, i.e., it has a higher content of saturated fatty acids.

Fig. 5 shows that no FAME and triacetin yields were obtainable at reaction condition of $300^{\circ} \mathrm{C} / 20 \mathrm{MPa}$ for both feedstocks. Furthermore, under $350^{\circ} \mathrm{C} / 20 \mathrm{MPa}$, at longer reaction times than $45 \mathrm{~min}$, reductions of FAME and triacetin were noticeable. As expected, the use of higher reaction temperature of $380^{\circ} \mathrm{C} / 20 \mathrm{MPa}$ resulted in more thermal decomposition in both oils.

The use of oil from oil palm that has considerable amount of saturated fatty acid did not prevent thermal decomposition from taking place. This situation was most likely due to the presence of unsaturated 
fatty acid in the feedstock, which is also vulnerable to thermal decomposition, particularly at such a severe reaction condition. This result, however, is contradict the results reported by Niza et al. (2011) and Tan et al. $(2010,2011)$ that suggested even a higher reaction temperature of $399^{\circ} \mathrm{C} / 59 \mathrm{~min}$ and $400^{\circ} \mathrm{C} / 32 \mathrm{~min}$, respectively, as their optimum reaction conditions for supercritical methyl acetate method for the biodiesel production from palm oil.

\subsection{Cis-trans isomenization of FAME}

Cis-trans isomerization of individual FAME can be used to indicate the cold-flow properties of biodiesel. Most natural fatty acids with double carbon bonds have cis-isomer structure that makes them have lower melting points. Imahara et al. (2008) reported that cis-trans isomerization happens during biodiesel production process by supercritical methanol, particularly when relatively high reaction temperatures are applied.

Using the same method as Imahara et al. (2008), identification of cis- and trans-types $\mathrm{C}=\mathrm{C}$ was done by recognizing FT-IR spectra peaks at wavenumber of 690 and $970 \mathrm{~cm}^{-1}$, respectively. Methyl stearate (C18:0) that has no double carbon bond was used as a control to show that there was neither cis- nor trans-isomers formed at any reaction conditions. On the other hand, FT-IR spectra from methyl oleate (C18:1), methyl linoleate (C18:2) and methyl linolenate (C18:3) show the 
appearance of trans-isomer peak as a compensation of the disappearance of the cis-isomer peak.

For poly-unsaturated FAME, at the most severe reaction condition used in this experiment, i.e., $380^{\circ} \mathrm{C}$, the appearance of trans-type $\mathrm{C}=\mathrm{C}$ peak was very observable. From these lines of evidence, it is clear that the use of very high reaction temperatures is not preferable in preventing cis-transisomerization of poly-unsaturated FAME.

\subsection{Decomposition of tocopherols}

Tocopherols as natural anti-oxidants are proven to be present in some biodiesel feedstocks and can provide anti-oxidant effect in biodiesel produced from those feedstocks (Fröhlich and Schober, 2007; Xin et al., 2008). However, the presence of tocopherols can be affected by the production process of biodiesel, due particularly to their vulnerability towards decomposition at high temperatures. Table 2 shows the effect of various reaction temperatures in supercritical methyl acetate treatments on the presence of tocopherols in FAME from rapeseed and oil palm.

From the table, we can see that the initial tocopherol content in FAME from oil palm was 450ppm, higher than that from rapeseed FAME, i.e., $300 \mathrm{ppm}$. Reaction temperatures below $300^{\circ} \mathrm{C}$ could prevent significant tocopherol reduction. The higher reaction temperatures resulted in more reduction of tocopherol contents in FAME. However, as mentioned earlier, due to the lower reactivity of triglycerides towards 
supercritical methyl acetate, the use of $350^{\circ} \mathrm{C}$ was unavoidable since at this temperature, the highest FAME and triacetin yields were obtainable.

At the higher reaction temperature of $380^{\circ} \mathrm{C}$, tocopherol contents were considerably reduced to 70 and 30ppm in oil palm and rapeseed FAME, respectively, which were much less than their original concentrations. Higher reaction temperatures as proposed by other research groups (Tan et al., 2011; Niza et al., 2011) will, therefore, further diminish more tocopherol in biodiesel. Such lower anti-oxidant content makes biodiesel more susceptible to oxidation, particularly during its storage.

\section{Concluding remarks}

This study showed that reaction temperature, pressure, time and molar ratio of methyl acetate to oil were the key parameters in biodiesel production by the supercritical methyl acetate method. Furthermore, evaluations on thermal decomposition, cis-trans isomerization and tocopherol content were necessary for determining an optimum condition. The reaction condition with the highest FAME and triacetin yields was, therefore, $350^{\circ} \mathrm{C} / 20 \mathrm{MPa} / 45 \mathrm{~min} / 42$ molar ratio. However, at such a reaction condition, we could not totally avoid the occurrence of thermal decomposition, thus, an optimum condition was not entirely attainable in this reaction system. 


\section{Reference}

1. Bonet J, Costa J, Sire R, Reneaume J-M, Pleşu AE, Pleşu V, Bozga G (2009) Revalorization of glycerol: Comestible oil from biodiesel synthesis. Food Bioprod Proc 87:171-178.

2. Saka S (application: 19 Dec 2005; granted: 2 Oct 2009) Manufacturing method for fatty acid methyl esters. Japan Patent no. 4378534.

3. Saka S, Isayama Y (2009) A new process for catalyst-free production of biodiesel using supercritical methyl acetate. Fuel 88:1307-1313.

4. Goembira F, Matsuura K, Saka S (2012) Biodiesel production by various supercritical carboxylate esters. Fuel 97:373-378.

5. Tan KT, Lee KT, Mohamed AR (2010) A glycerol-free process to produce biodiesel by supercritical methyl acetate technology: An optimization study via Response Surface Methodology. Bioresour Technol 101:965-969.

6. Niza NM, Tan KT, Ahmad Z, Lee KT (2011) Comparison and optimization of biodiesel production from J atropha curcas oil using supercritical methyl acetate and methanol. Chemical papers 65(5):721-729.

7. Tan KT, Lee KT, Mohamed AR (2011) Prospects of non-catalytic supercritical methyl acetate process in biodiesel production. Fuel Proc Technol 92:1905-1909.

8. Campanelli, P, Banchero M, Manna L (2010) Synthesis of biodiesel from edible, non-edible and waste cooking oils via supercritical methyl acetate transesterification. Fuel 89:3675-3682.

9. Saka S, Goembira F, Ilham Z (2011) Letter to the Editors: Comment on "A glycerol-free process to produce biodiesel by supercritical methyl acetate technology: An optimization study via Response Surface Methodology". Bioresour Technol 102:3989. 
10. Imahara H, Minami E, Hari S, Saka S (2008) Thermal stability of biodiesel in supercritical methanol. Fuel 87:1-6.

11. Xin J, Imahara H, Saka S (2008) Oxidation stability of biodiesel fuel as prepared by supercritical methanol. Fuel 87:1807-1813.

12. Ehara K, Saka S, Kawamoto H (2002) Characterization of the ligninderived products from wood as treated in supercritical water. J Wood Sci 48:320-325.

13. Turro NJ (2005) Molecular structure as a blueprint for supramolecular structure chemistry in confined spaces. PNAS 2(31):10766-10770.

14. Ilham Z, Saka S (2010) Two-step supercritical dimethyl carbonate method for biodiesel production from J atropha curcas oil. Bioresour Technol 101:2735-2740.

15. Fröhlich A, Schober S (2007) The influence of tocopherols on the oxidation stability of methyl esters. J Amer Oil Chem Soc 4:579-585. 


\section{Figure Captions}

Fig. 1 Effect of molar ratio in methyl acetate to oil on FAME and triacetin yields from rapeseed oil as treated in supercritical methyl acetate at $350^{\circ} \mathrm{C} / 20 \mathrm{MPa}$

Fig. 2 Effect of reaction pressure on FAME and triacetin yields from rapeseed oil as treated in supercritical methyl acetate at $350^{\circ} \mathrm{C}$ and molar ratio of $42: 1$ in methyl acetate to oil

Fig. 3 Effect of reaction temperature on FAME and triacetin yields from rapeseed oil as treated in supercritical methyl acetate at $20 \mathrm{MPa}$ and molar ratio of 42:1 in methyl acetate to oil

Fig. 4 Recovery of various FAME and triacetin as exposed to supercritical methyl acetate at 20MPa under different reaction temperatures and times

Fig. 5 FAME and triacetin yields from oils of rapeseed (Brassic a napus) and oil palm (Elaeis guineensis) as treated in supercritical methyl acetate under various reaction temperatures at $20 \mathrm{MPa}$ and 42 molar ratio 
Table 1 Fatty acid composition of oils from rapeseed (Brassica napus) and oil palm (Ela eis guineensis)

\begin{tabular}{lcccccc}
\hline \multirow{2}{*}{ Oil So urce } & \multicolumn{5}{c}{ Fatty Acid Composition (wt\%) } \\
\cline { 2 - 6 } & C16:0 & C18:0 & C 18:1 & C 18:2 & C 18:3 & Others \\
\hline Rapeseed & 4.0 & 1.7 & 62.5 & 21.2 & 9.0 & 1.6 \\
Oil Palm & 40.0 & 4.3 & 43.5 & 10.8 & 0.2 & 1.2 \\
\hline
\end{tabular}


Table 2 Effect of various reaction temperatures on the tocopherol content in FAME from oil palm and rapeseed as treated in superc ritic al methyl aceta te at 20MPa for 30min

\begin{tabular}{ccccccc}
\hline \multirow{2}{*}{ FAME } & \multicolumn{5}{c}{ Tocopherol Content (ppm) } \\
\cline { 2 - 7 } & Unexposed & $270^{\circ} \mathrm{C}$ & $300^{\circ} \mathrm{C}$ & $320^{\circ} \mathrm{C}$ & $350^{\circ} \mathrm{C}$ & $380^{\circ} \mathrm{C}$ \\
\hline Rapeseed & 300 & 296 & 289 & 270 & 87 & 30 \\
Oil Pa Im & 450 & 447 & 438 & 425 & 150 & 70 \\
\hline
\end{tabular}



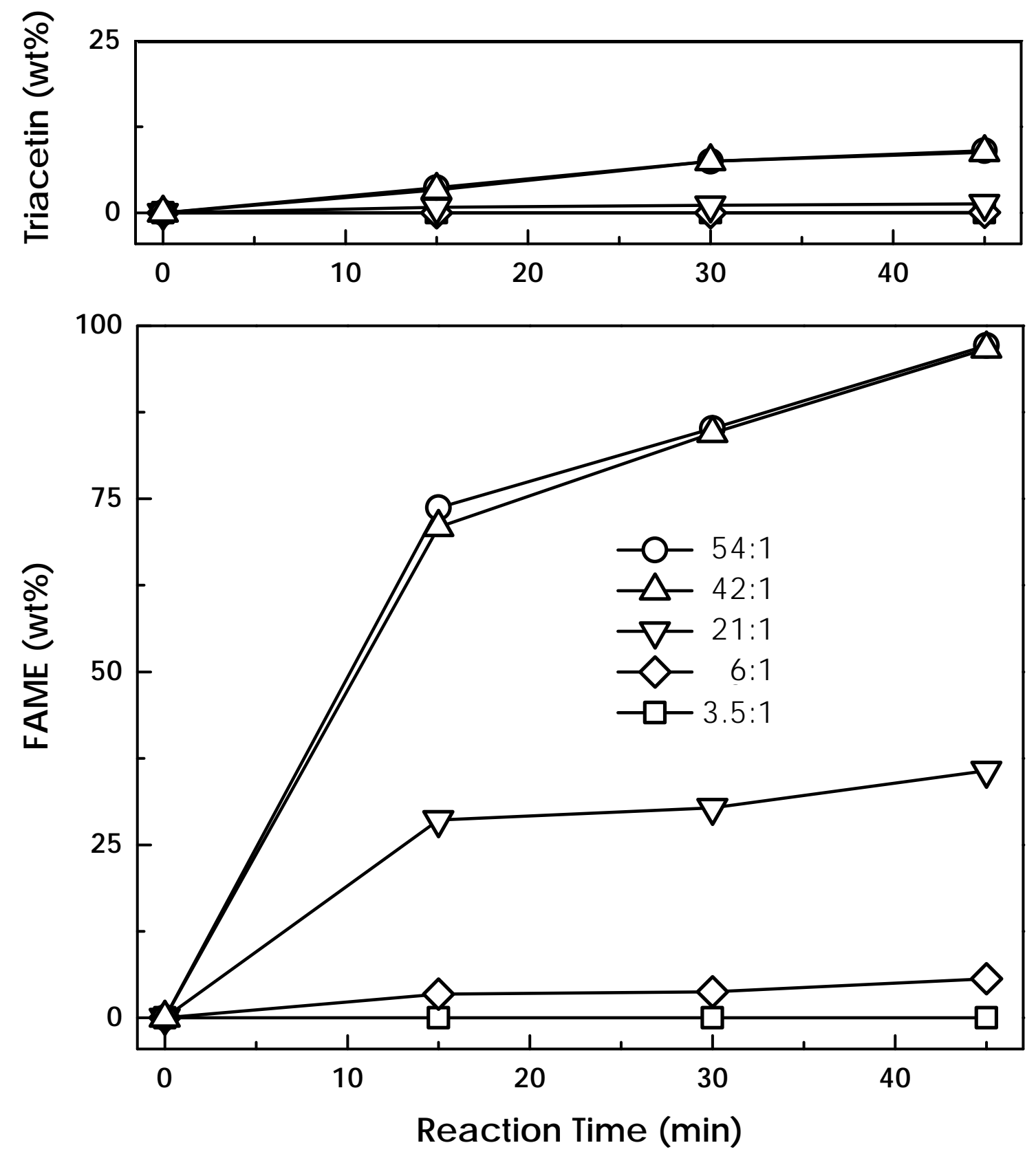

Fig. 1 Effect of molar ratio in methyl acetate to oil on FAME and triac etin yields from ra peseed oil as treated in superc ritic al methyl a cetate at $350^{\circ} \mathrm{C} / 20 \mathrm{MPa}$ 

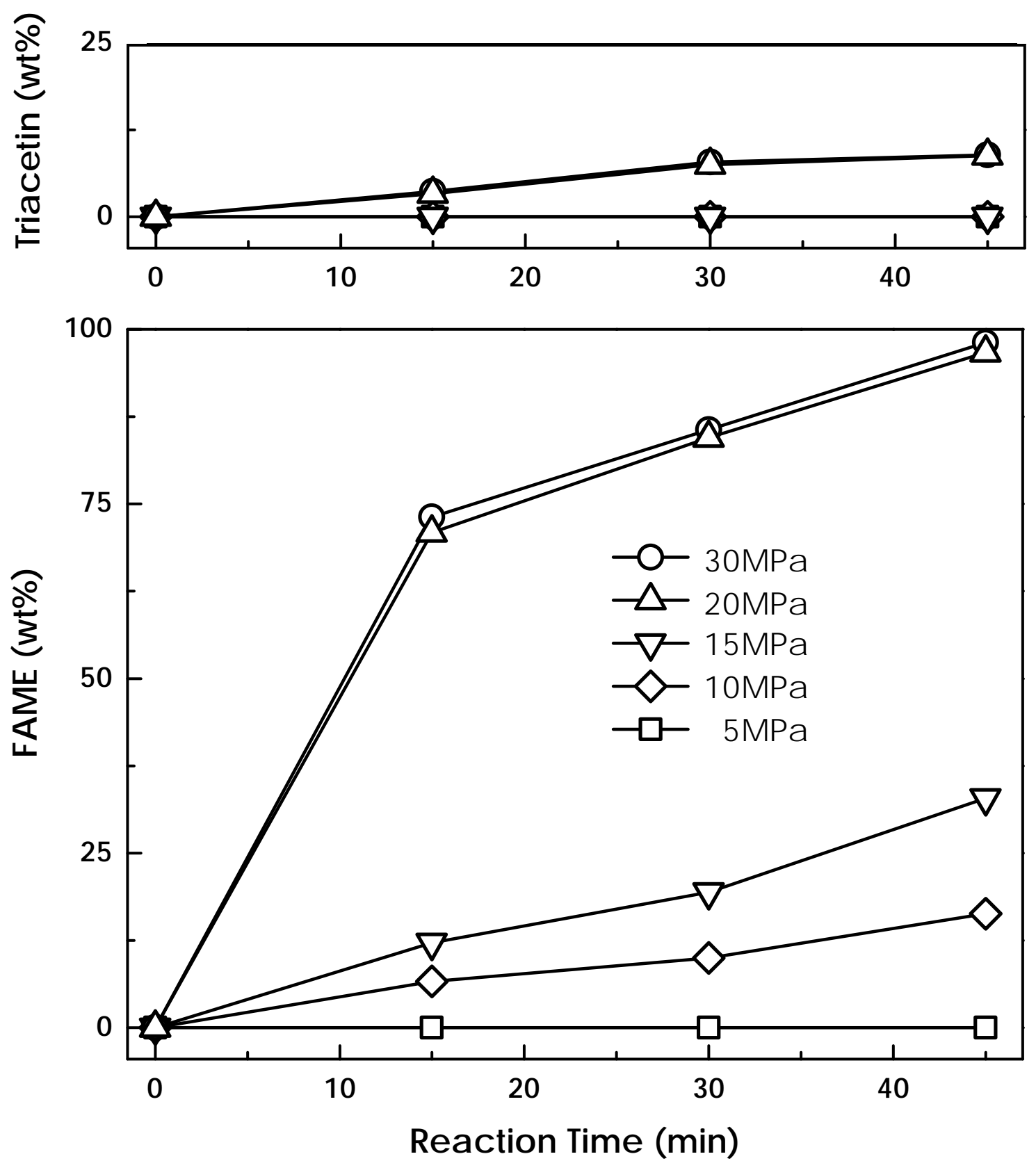

Fig. 2 Effect of reaction pressure on FAME and triacetin yields from rapeseed oil as treated in supercritical methyl acetate at $350^{\circ} \mathrm{C}$ and molar ratio of $42: 1$ in methyl acetate to oil 

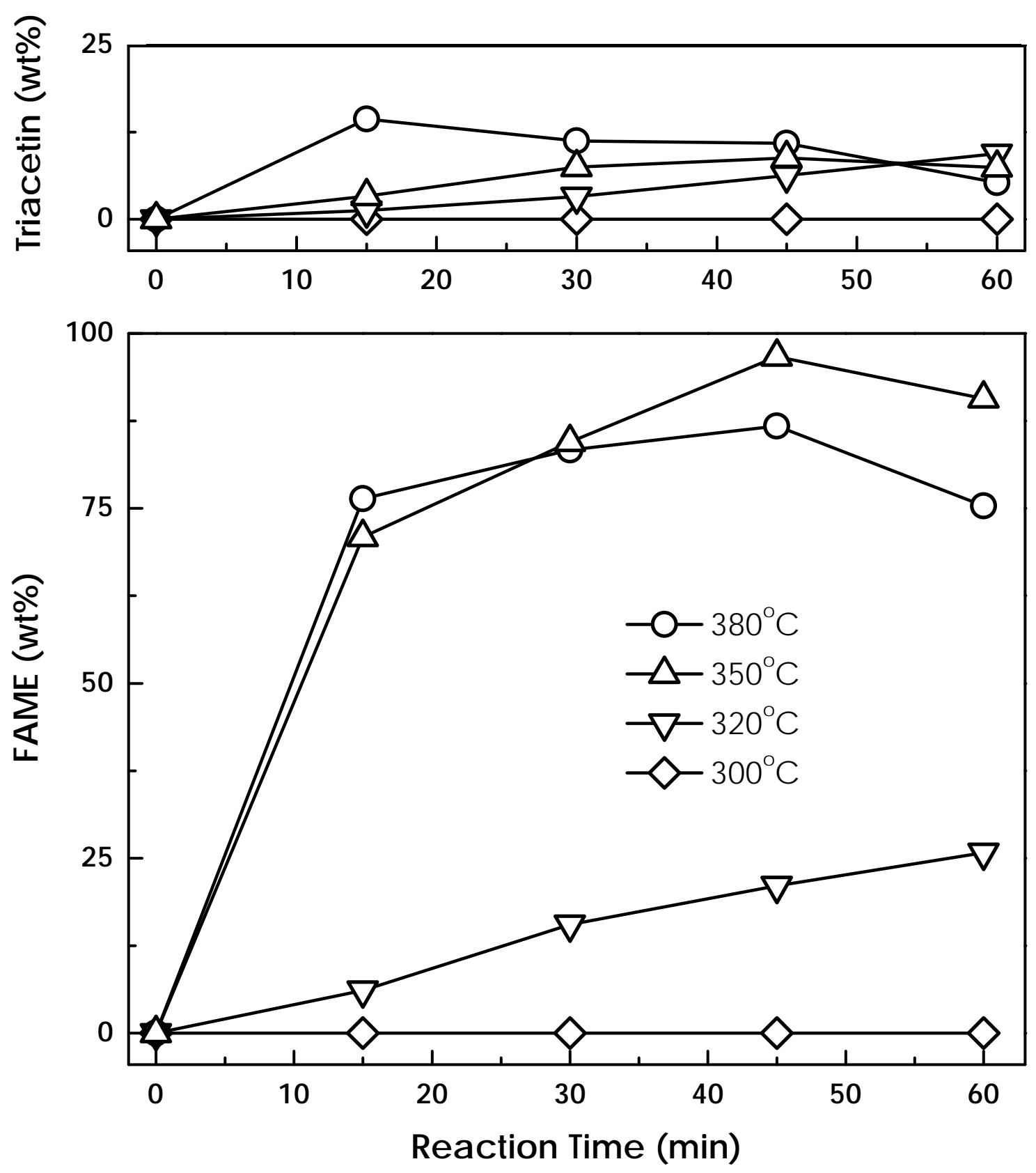

Fig. 3 Effect of reaction temperature on FAME and triacetin yields from rapeseed oil as treated in superc itical methyl acetate at 20MPa and molar ratio of $42: 1$ in methyl acetate to oil 
a) Methyl Palmitate (16:0)



c) Methyl Oleate (18:1)

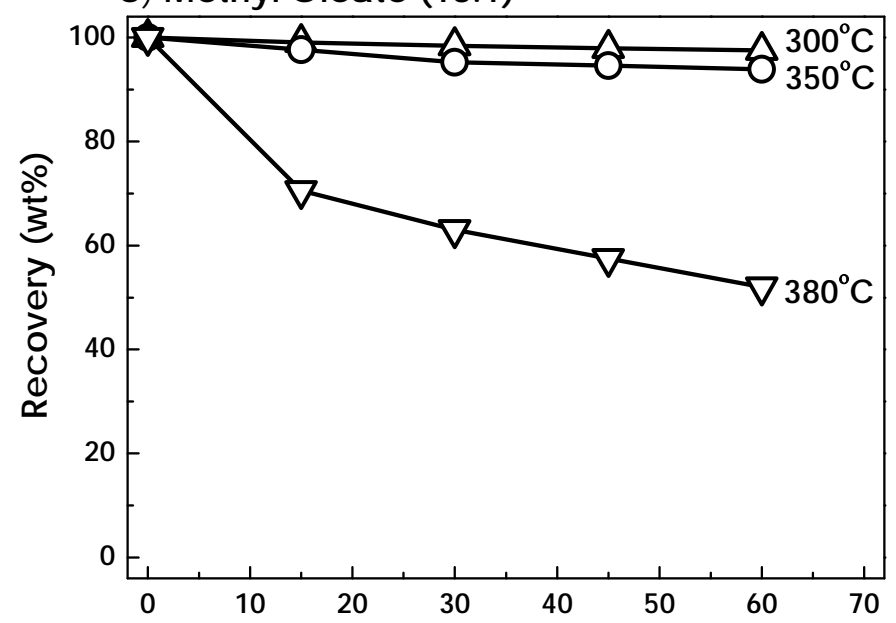

e) Methyl Linolenate (18:3)

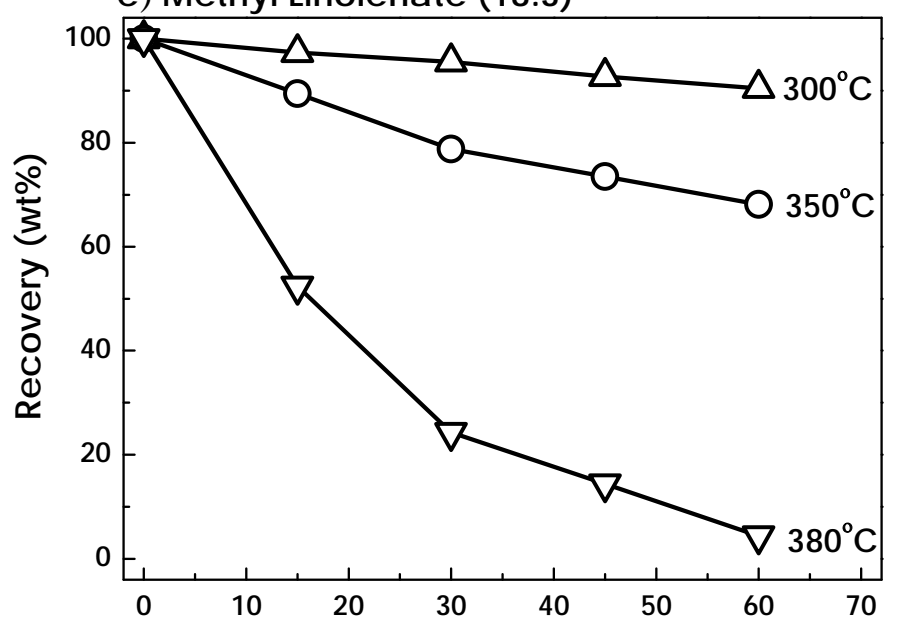

Exposure Time (min) b) Methyl Stearate (18:0)

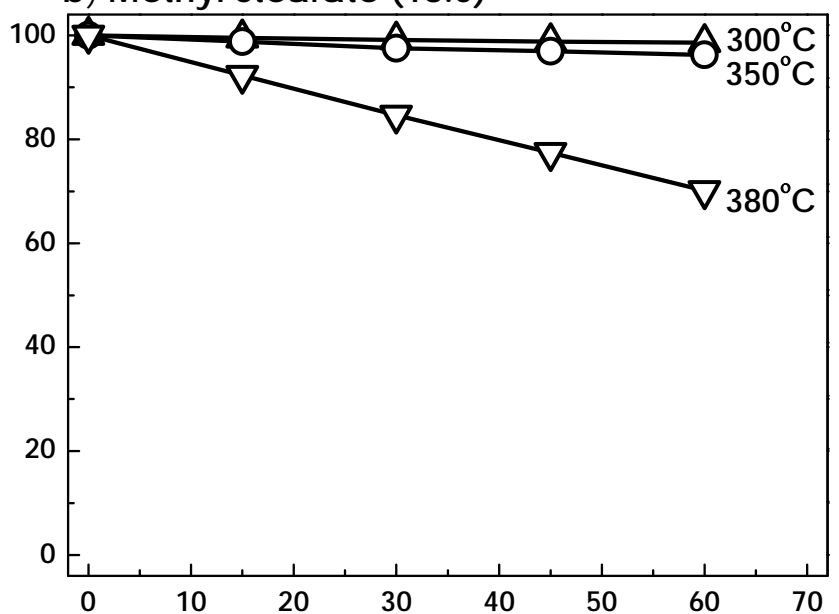

d) Methyl Linoleate (18:2)
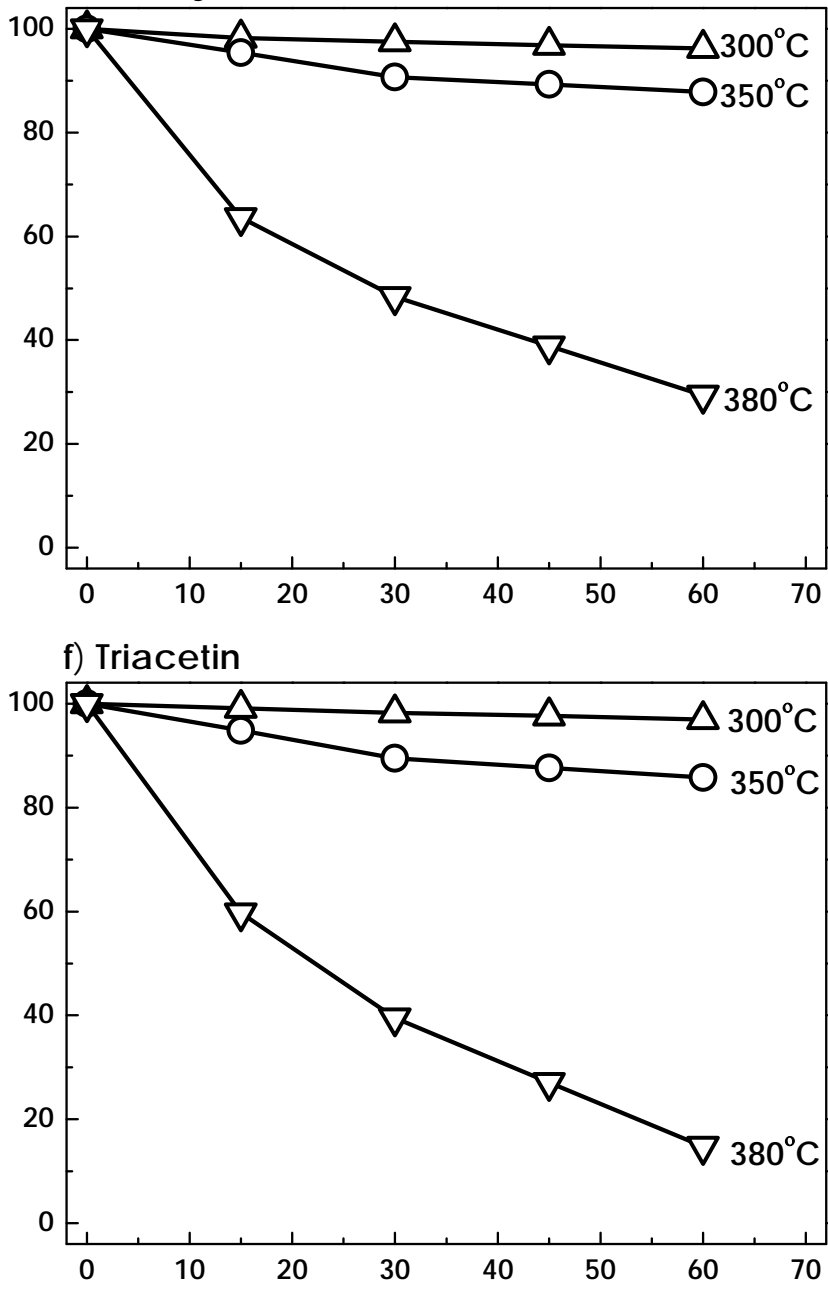

Exposure Time (min)

Fig. 4 Recovery of various FAME and triacetin as exposed to superc ritical methyl acetate at 20MPa under different reaction temperatures and times 


\section{a) Rapeseed}
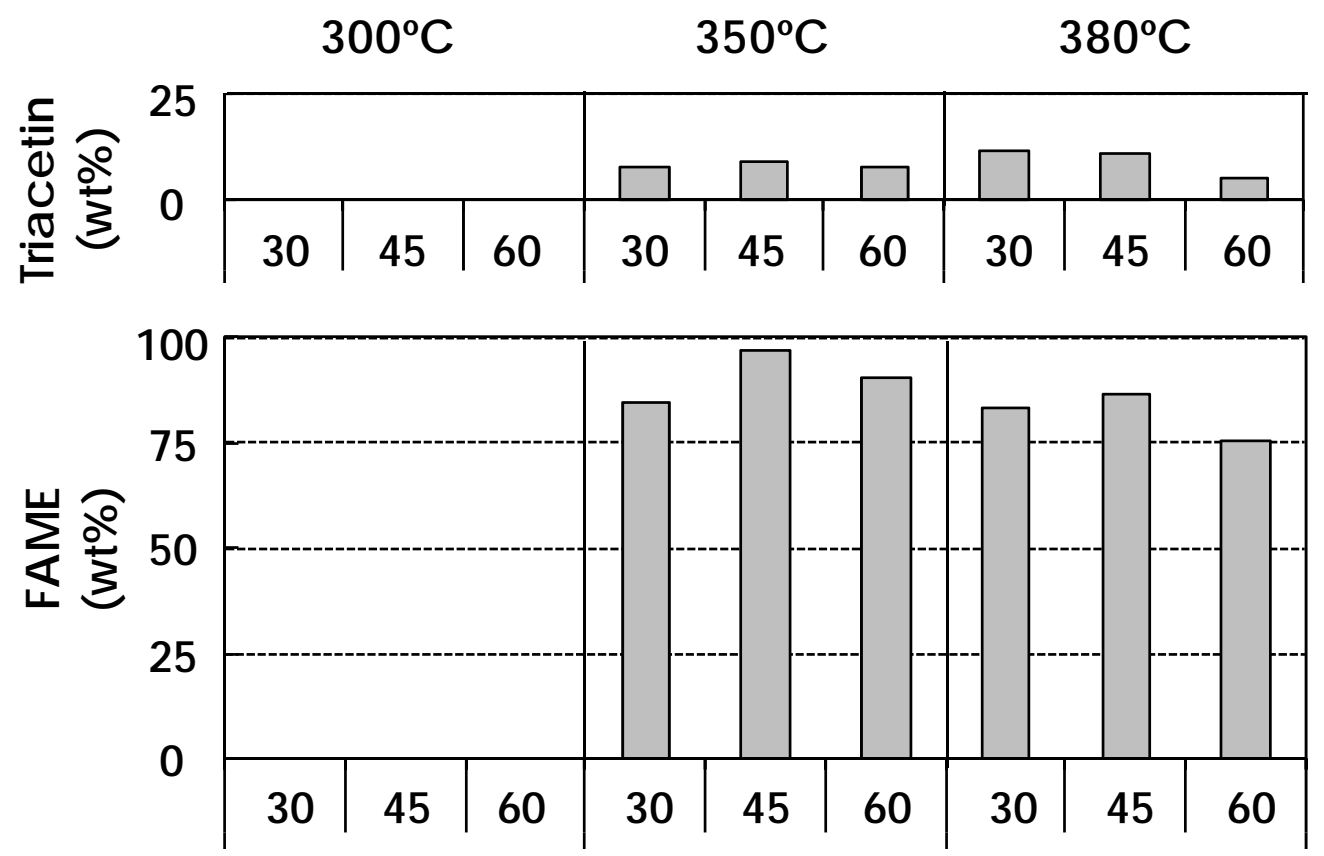

b) Oil Palm
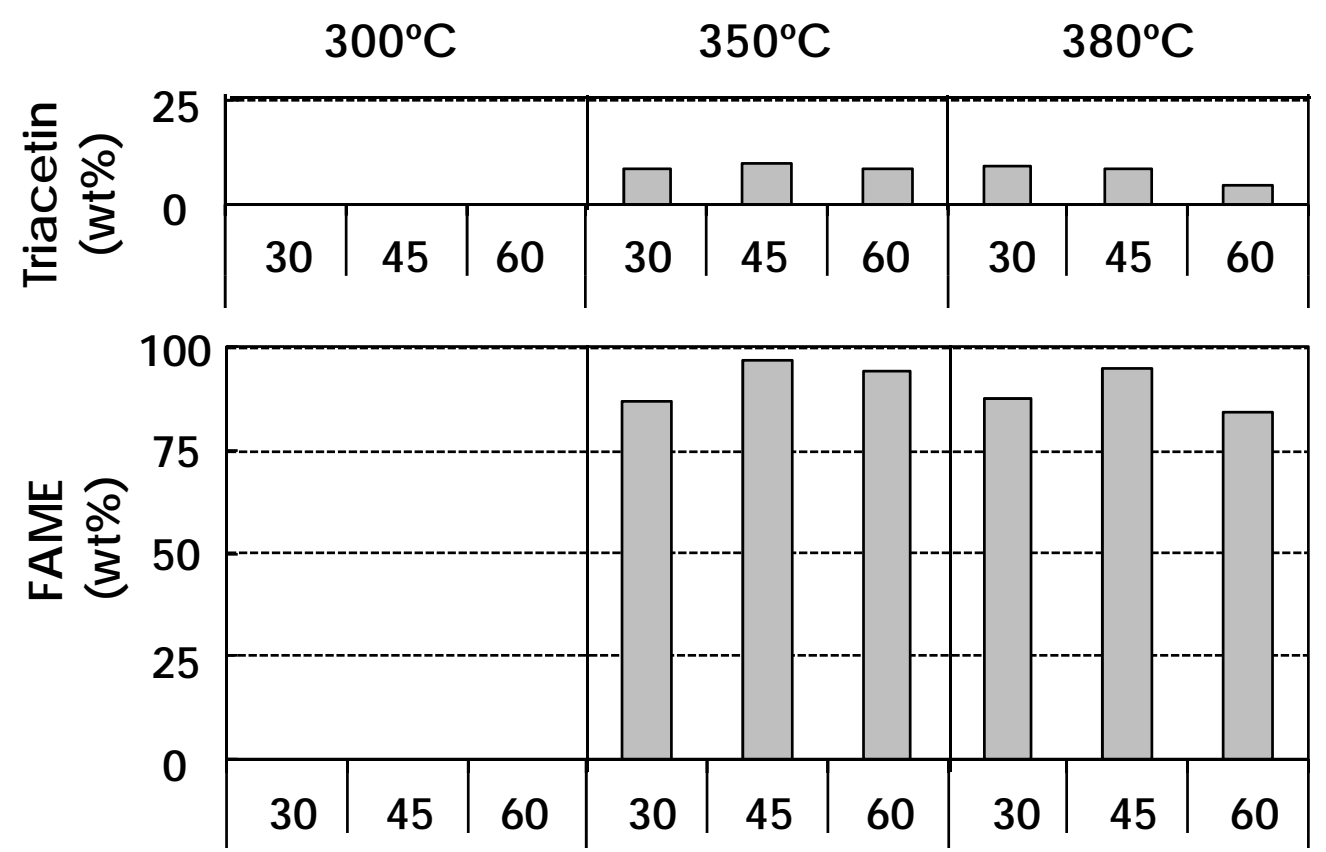

Reaction Time (min)

Fig. 5 FAME and triacetin yields from oils of rapeseed (Brassica napus) and oil palm (Elaeis guineensis) as treated in supercritical methyl acetate under various reaction temperatures at 20MPa and 42 molar ratio 